29. Dousset V, Armand JP, Lacost D, et al. Magnetization transfer study of HIV encephalitis and progressive multifocal leukoencephalopathy. AJNR Am J Neuroradiol 1997;18: 895-901.

30. Silver NC, Barker GJ, MacManus DG, et al. Decreased magnetization transfer ratio due to demyelination: a case of central pontine myelinilysis. J Neurol Neurosurg Psychiatry 1996;61:208-209.

31. Filippi M, Campi A, Colombo B, et al. A spinal cord MRI study of benign and secondary progressive multiple sclerosis. J Neurol 1996;243:502-505.

32. Stevenson VL, Leary SM, Losseff NA, et al. Spinal cord atrophy and disability in MS. A longitudinal study. Neurology 1998;51:234-238.

33. Davie CA, Barker GJ, Thompson AJ, Tofts PS, McDonald WI, Miller DH. ${ }^{1} \mathrm{H}$ magnetic resonance spectroscopy of chronic cerebral white matter lesions and normal appearing white matter in multiple sclerosis. J Neurol Neurosurg Psychiatry 1997;63:736-742.

34. Thompson AJ, Kermode AG, Wicks D, et al. Major differences in the dynamics of primary and secondary progressive multiple sclerosis. Ann Neurol 1991;29:53-62.

35. Truyen L, van Waesberghe JHTM, van Walderveen MAA, et al. Accumulation of hypointense lesions ("black holes") on T1 spin-echo MRI correlates with disease progression in multiple sclerosis. Neurology 1996;47:1469-1476.

36. Phillips MD, Grossman RI, Miki Y, et al. Comparison of T2 lesion volume and magnetization transfer ratio histogram analysis and of atrophy and measure of lesion burden in patients with multiple sclerosis. AJNR Am J Neuroradiol 1998; 19:1055-1060.

37. Fu L, Matthews PM, De Stefano N, et al. Imaging axonal damage of normal-appearing white matter in multiple sclerosis. Brain 1998;121:103-113.

\title{
Neuro/mages
}
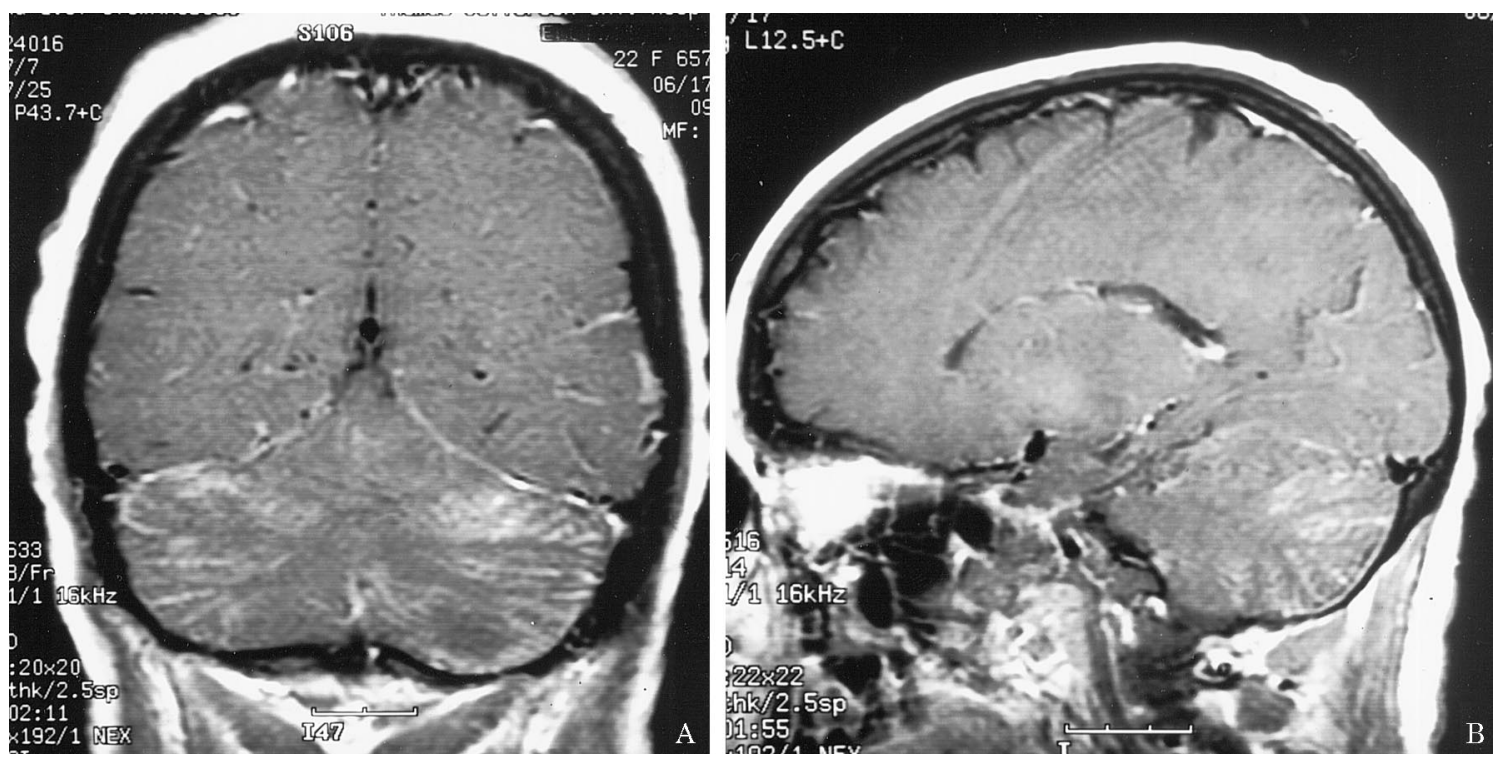

Figure. Coronal and sagittal sections of brain MRI after gadolinium administration. Both demonstrate moderately extensive abnormal leptomeningeal enhancement in the posterior fossa and subtle increased enhancement in the leptomeninges of the supratentorial brain. The cerebellum looks swollen.

\section{Acute cerebellitis: MRI findings}

Vinutha Ravi, MD, Todd D. Rozen, $M D$,

Philadelphia, PA

A 22-year-old woman with a history of sickle cell disease presented with a throbbing holocranial headache, fever, and chills. The headache was associated with photophobia, nausea, and neck stiffness. There was no evidence of meningismus.

Neurologic examination was significant for wide-based unsteady gait with mild ataxia. There was no dysmetria or ataxic dysarthria. Laboratory evaluation demonstrated an elevated serum white count with shift. CSF examination showed a lymphocytic pleocytosis with elevated total protein, normal glucose, and negative Gram stain and bacterial cultures, suggestive of an aseptic or viral meningitis.

CT of the brain at admission demonstrated hydrocephalus. MRI of the brain revealed cerebellar swelling. Postga- dolinium administration, there was bilateral cerebellar enhancement with only mild supratentorial enhancement (figure), suggesting an inflammatory process strictly involving the cerebellum.

A clinical diagnosis of acute cerebellitis was made, most likely viral induced, as no systemic infection (blood and urine cultures were negative) was found. Her symptoms improved with fluid hydration and no antibiotics. A follow-up MRI was suggested but not completed.

Abnormal bilateral cerebellar enhancement on MRI has been documented in one other case of acute cerebellitis. ${ }^{1}$ It appears that cerebellar enhancement on MRI may be a specific imaging test for acute cerebellitis.

1. Bakshi R, Bates VE, Kinkel PR, Mechtlee LL, Kinkel WR. Magnetic resonance imaging findings in acute cerebellitis. Clin Imaging 1998;22: $79-85$. 


\section{Neurology}

\section{Acute cerebellitis: MRI findings}

Neurology 2000;54;213

DOI 10.1212/WNL.54.1.213

This information is current as of January 11, 2000

\section{Updated Information \&} Services

Permissions \& Licensing

\section{Reprints}

including high resolution figures, can be found at: http://n.neurology.org/content/54/1/213.full

Information about reproducing this article in parts (figures,tables) or in its entirety can be found online at:

http://www.neurology.org/about/about_the_journal\#permissions

Information about ordering reprints can be found online:

http://n.neurology.org/subscribers/advertise

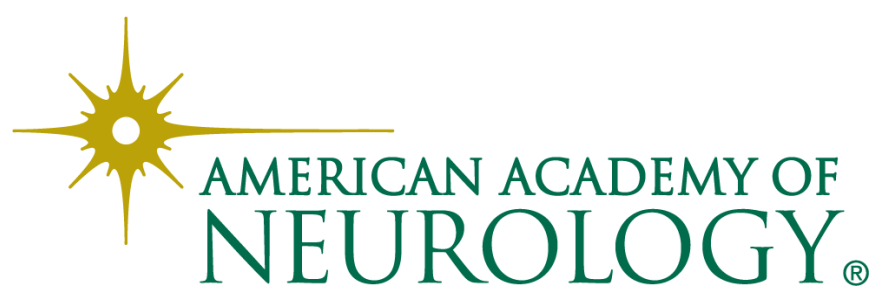

